\title{
Multicriteria analysis for design of microirrigation systems. Application and sensitivity analysis
}

\author{
C.M.G. Pedras ${ }^{a, b}$, L.S. Pereira ${ }^{b, *}$ \\ ${ }^{a}$ FERN, University of Algarve, Campus de Gambelas, 8005-139 Faro, Portugal \\ ${ }^{\mathrm{b}}$ Agricultural Engineering Research Center, Institute of Agronomy, Technical University of Lisbon, \\ Tapada da Ajuda, 1349-017 Lisbon, Portugal
}

\section{A R T I C L E I N F O}

Article history:

Received 7 April 2008

Accepted 22 October 2008

Published on line 9 December 2008

\section{Keywords:}

Microirrigation design

Multicriteria analysis

Criteria weights

Concordance and discordance

thresholds

Ranking

\begin{abstract}
A B S T R A C T
This paper presents a practical application of the DSS MIRRIG for the design of a microirrigation system for a citrus orchard in Algarve (Portugal). Several alternatives were considered using different emitter types (drippers, sprayers, pressure-compensating and non-pressure compensating emitters), different pipe sizes and layouts with and without pressure regulation valves, as well as different pressure head and discharge at the upstream end of the systems. This application is described and the ranking of alternative designs is analysed using the weights given by the farmer to the hydraulic, economic and environmental criteria. An analysis of impacts resulting from selecting different weights is presented aimed at understanding the sensitivity of the model in relation to those criteria. In addition, a sensitivity analysis is performed to test the robustness of the algorithms used for ranking with respect to changes in concordance and discordance threshold values, which show that the values selected by the model are those providing for a more clear ranking of design alternatives.
\end{abstract}

(C) 2008 Elsevier B.V. All rights reserved.

\section{Introduction}

Design of microirrigation systems is complex because it comprises the selection of emitters, pipes and respective layout, and decisions on pressure head and its variation along the system, as well as pressure and discharge regulators and filters (Keller and Bliesner, 1990; ASAE, 2006).

The selection of the emitters is difficult because there are a large variety of emitters, in- and on-line drippers and microsprayers whose characteristics may satisfy the irrigation requirements in relation to the crop, the soil and the land topography. However, different emitters have different requirements in terms of pipe layouts, operation pressure and pressure regulation, and leading to different system performance (Keller and Bliesner, 1990; Pereira and Trout, 1999). A variety of criteria and calculation procedures may be used to size the pipe system and limit pressure and discharge variations in the system (Wu and Barragan, 2000; Demir et al., 2007). Advances in design are proposed aimed at attaining targets on emission uniformity or economic objectives (Barragan et al., 2006; Valiantzas et al., 2007).

Decisions taken at the design stage have a permanent effect on the performance of the system and imply additional costs if the system has to be modified later. Some decisions involve the simultaneous consideration of different objectives, which are often in conflict, e.g., minimizing costs and maximizing profits can be in conflict with minimizing environmental impacts and maximizing irrigation uniformity. Limiting investment and operation costs and maximising incomes are generally the most important factors that farmers take into consideration when selecting a new irrigation system. The performance of microirrigation systems depends

\footnotetext{
* Corresponding author at: Agricultural Engineering Research Center, Institute of Agronomy, Technical University of Lisbon, Tapada da Ajuda, 1349-017 Lisbon, Portugal. Tel.: +351 213653339; fax: +351 213621575.

E-mail addresses: cpedras@ualg.pt (C.M.G. Pedras), lspereira@isa.utl.pt (L.S. Pereira). 0378-3774/\$ - see front matter (C) 2008 Elsevier B.V. All rights reserved.

doi:10.1016/j.agwat.2008.10.007
} 
essentially on the type and quality of the equipment and on the quality of the system design. Fortunately, a better control of negative environmental impacts of irrigation is achieved when the system performance is high; however, attaining a high performance usually requires higher investment costs.

Finding compromise solutions is better supported by adopting multicriteria analysis (MCA) to rank design alternatives. Using a decision support system (DSS) for design is helpful to find the best design alternatives, as analysed in the companion paper where the DSS MIRIG is presented (Pedras et al., 2008). It is therefore important to analyse how the weights assigned to the design criteria expressing the preferences of the user influence ranking, and how the selection of concordance and discordance thresholds influence the process of selecting alternatives. The corresponding analysis of sensitivity of MIRRIG is therefore the objective of this paper, so complementing the DSS presentation in the mentioned companion paper.

\section{Material and methods}

\subsection{The DSS MIRRIG}

The decision support system MIRRIG (Pedras et al., 2008) includes (Fig. 1): (1) a database on emitters, pipes, crops, soils and systems, (2) a module for sizing the system, (3) a performance analysis module that simulates the functioning of the system and computes the relevant performance indicators used as attributes of the decision criteria, and (4) a decision criteria module using the ELECTRE II (Roy, 1996) multicriteria analysis to rank the alternative design options. Different user selected weights may be assigned to the criteria, as well as user selected concordance and discordance thresholds.

The user creates a number of design alternatives relative to the pipe system and the emitters, drippers or microsprayers. For each alternative, the pipe system is sized through an iterative calculation procedure and its functioning is simulated. As a result, a set of performance, economic and environmental

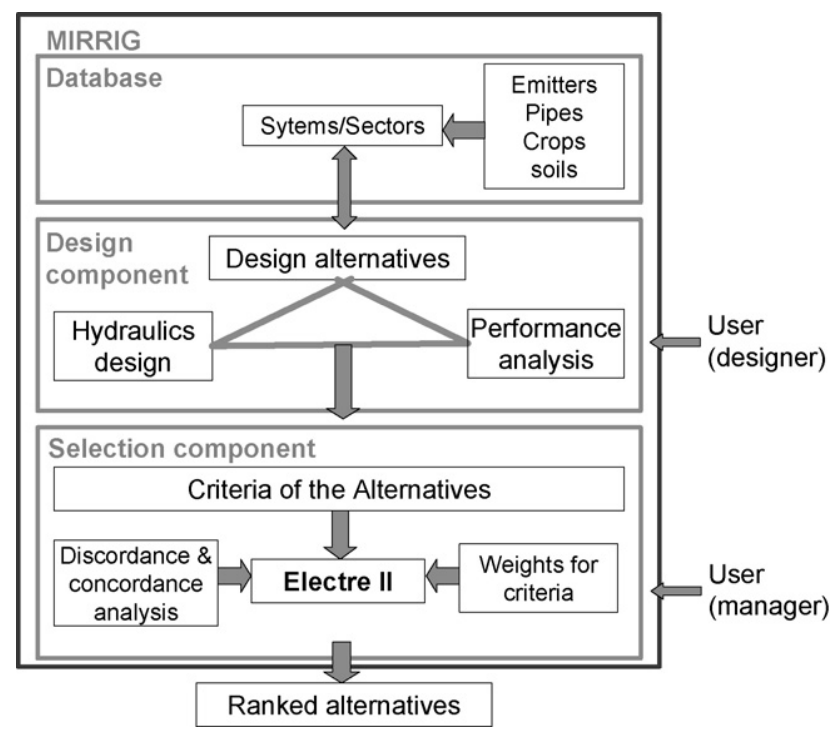

Fig. 1 - Conceptual design structure of the DSS MIRRIG. indicators are computed that characterize each alternative (Pedras et al., 2008). These indicators are used to build the attributes relative to the selected criteria listed in Table 1 . In addition, emitters characteristics relative to sensitivity to clogging (SC) and sensitivity of emitters to temperature variation (STV) are also used as attributes. SC refers to the diameter of the emitter passageway and the emitter capability of flushing, and STV is related to the material and the flow regime of the emitter (Rodríguez-Sinobas et al., 1999). MCA is then applied to compare and rank the alternatives using weights and concordance and discordance thresholds selected by the user. The objectives and criteria attributes adopted in MIRRIG are listed in Table 1.

The ELECTRE II is an outranking MCA method (Roy, 1996) aimed at supporting decisions by ranking alternative solutions for a multiobjective problem. It is based on a pair wise comparison of alternatives and evaluates the degree to which scores in the criteria and their associated weights confirm or contradict the dominance in the pair wise relationships. The final ranking is based on the strong and weak outranking relations calculated with the use of concordance and discordance thresholds. Therefore, ELECTRE II allows evaluating and ranking that takes into consideration various aspects that influence the system performance and related economic and environmental impacts, and it also can provide interactive support to advice farmers on required improvements relative to design options. To find a compromise solution between environmental and economic criteria, the decision maker can decide among different options depending on the weights assigned to environmental and economic criteria.

To assess the sensitivity of the model to the weights assigned to the criteria, ranking was performed for constant values of the concordance and discordance thresholds when adopting different sets of weights. Similarly, aiming at assessing the sensitivity of the model to the selected values for the concordance and discordance thresholds, ranking was performed adopting various sets of concordance or discordance thresholds while using a given set of criteria weights.

Table 1 - Objectives and attributes relative to the criteria used for ranking the alternatives.

\begin{tabular}{|c|c|}
\hline Objectives & Criteria attributes \\
\hline Minimizing costs & $\begin{array}{l}\text { Annual fixed cost, AFC } \\
\text { Operation and maintenance } \\
\text { cost, OMC }\end{array}$ \\
\hline Maximizing yields & $\begin{array}{l}\text { Percentage of deficit relative } \\
\text { to the required application } \\
\text { depth, } P_{D}\end{array}$ \\
\hline $\begin{array}{l}\text { Minimizing } \\
\text { environmental impacts }\end{array}$ & $\begin{array}{l}\text { Volume of water percolated } \\
\text { out of the root zone } \\
\text { indicating the potential } \\
\text { contamination with nitrates } \\
\text { and agricultural chemicals, } V_{p}\end{array}$ \\
\hline \multirow{2}{*}{$\begin{array}{l}\text { Maximizing irrigation } \\
\text { performance }\end{array}$} & Emission uniformity, EU \\
\hline & $\begin{array}{l}\text { Sensitivity to clogging, SC } \\
\text { Sensitivity of emitters to tem- } \\
\text { perature variation, STV }\end{array}$ \\
\hline
\end{tabular}




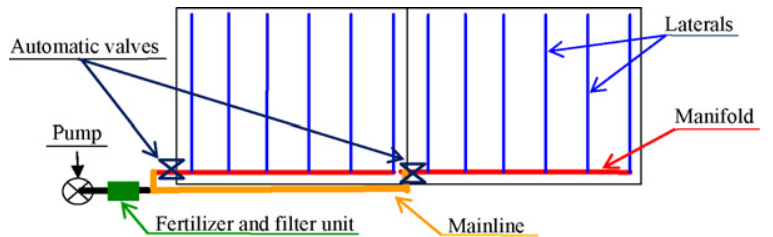

Fig. 2 - Schematic layout of the irrigation system.

\subsection{Case study}

The case study refers to a citrus orchard (2.6 ha) in Faro, Southern Portugal, where the trees spacing is $3 \mathrm{~m} \times 5 \mathrm{~m}$. The irrigation system has 2 sectors (Fig. 2), with the manifold located on the highest part of the sector. Water is supplied at the lowest end, where the well is located. Each sector has only one manifold. The length of the laterals is $105 \mathrm{~m}$, with a $1.9 \%$ downhill slope. The manifold has an uphill slope of $0.8 \%$. Several drip and microspray emitters were considered, for a total of 41 alternatives. For the drippers' alternatives, the emitters spacing is $1 \mathrm{~m}$ and there are two laterals per tree row; for the microspray alternatives there is 1 emitter per tree and 1 lateral per tree row. These pipe layout options were selected to produce an appropriate wetting of the citrus root area. The average gross daily irrigation depth is $6 \mathrm{~mm}^{\text {day }}{ }^{-1}$.

\section{Results}

\subsection{Design alternatives}

A total of 41 design alternatives were generated with MIRRIG. They refer to the emitters characteristics. The layout of the

Table 2 - Characteristics of the emitters.

\begin{tabular}{|c|c|c|c|c|c|c|}
\hline $\begin{array}{l}\text { Alternative } \\
\text { number }\end{array}$ & $\begin{array}{l}\text { Emitter } \\
\text { type }^{\mathrm{a}}\end{array}$ & $\begin{array}{c}\text { Pressure } \\
\text { head, } H(\mathrm{~m})\end{array}$ & $\begin{array}{l}\text { Flow rate, } \\
q\left(\mathrm{~L} \mathrm{~h}^{-1}\right)\end{array}$ & $\begin{array}{l}\text { Discharge } \\
\text { coefficient }\end{array}$ & $\begin{array}{l}\text { Discharge } \\
\text { exponent }\end{array}$ & $\begin{array}{c}\text { Coefficient of } \\
\text { manufacturing variation }\end{array}$ \\
\hline 1 & Dripper & 10.0 & 4.0 & 1.2529 & 0.4998 & 0.015 \\
\hline 2 & Dripper & 10.0 & 4.1 & 1.3709 & 0.4723 & 0.02 \\
\hline 3 & Dripper & 10.0 & 5.0 & 1.3643 & 0.4780 & 0.015 \\
\hline 4 & Dripper-in & 10.0 & 3.7 & 1.1851 & 0.4966 & 0.04 \\
\hline 5 & Dripper-in & 10.0 & 3.7 & 1.1851 & 0.4966 & 0.04 \\
\hline 6 & Dripper & 10.0 & 3.8 & 4.3007 & -0.0546 & 0.05 \\
\hline 7 & Dripper-in & 10.0 & 4.4 & 1.4731 & 0.4784 & 0.04 \\
\hline 8 & Dripper-in & 10.0 & 3.6 & 1.1394 & 0.5014 & 0.04 \\
\hline 9 & Dripper-in & 10.0 & 2.6 & 3.4200 & 0.0200 & 0.04 \\
\hline 10 & Dripper-in & 10.0 & 4.4 & 4.0900 & 0.0300 & 0.04 \\
\hline 11 & Dripper-in & 10.0 & 3.4 & 3.3400 & 0.0130 & 0.05 \\
\hline 12 & Dripper-in & 10.0 & 3.4 & 3.3400 & 0.0130 & 0.05 \\
\hline 13 & Dripper-in & 10.0 & 3.4 & 3.3400 & 0.0130 & 0.05 \\
\hline 14 & Dripper & 10.0 & 4.0 & 1.4487 & 0.4414 & 0.05 \\
\hline 15 & Dripper-in & 10.0 & 3.0 & 1.0154 & 0.4645 & 0.04 \\
\hline 16 & Dripper-in & 10.0 & 2.8 & 0.9191 & 0.4875 & 0.04 \\
\hline 17 & Dripper-in & 10.0 & 4.1 & 1.2958 & 0.5003 & 0.04 \\
\hline 18 & Dripper-in & 10.0 & 3.9 & 1.2821 & 0.4840 & 0.04 \\
\hline 19 & Dripper-in & 10.0 & 3.2 & 1.0180 & 0.5003 & 0.04 \\
\hline 20 & Dripper-in & 10.0 & 4.7 & 1.4743 & 0.5033 & 0.04 \\
\hline 21 & Dripper-in & 10.0 & 3.1 & 0.9896 & 0.4964 & 0.04 \\
\hline 22 & Dripper-in & 10.0 & 3.6 & 3.1418 & 0.0610 & 0.05 \\
\hline 23 & Dripper & 10.0 & 3.9 & 2.8196 & 0.1409 & 0.03 \\
\hline 24 & Dripper & 10.0 & 3.8 & 3.9050 & -0.0125 & 0.05 \\
\hline 25 & Dripper-in & 10.0 & 3.6 & 1.1394 & 0.5014 & 0.04 \\
\hline 26 & Dripper-in & 10.0 & 4.4 & 1.4731 & 0.4784 & 0.04 \\
\hline 27 & Dripper & 10.5 & 3.4 & 2.7447 & 0.0992 & 0.03 \\
\hline 28 & Dripper-in & 10.5 & 3.5 & 3.2193 & 0.0317 & 0.05 \\
\hline 29 & Dripper & 10.5 & 3.9 & 3.6808 & 0.0239 & 0.02 \\
\hline 30 & Dripper & 10.5 & 4.0 & 1.2626 & 0.5000 & 0.03 \\
\hline 31 & Sprayer & 20.0 & 33.9 & 8.6000 & 0.4580 & 0.07 \\
\hline 32 & Sprayer & 20.0 & 43.5 & 11.0270 & 0.4580 & 0.07 \\
\hline 33 & Sprayer & 20.0 & 76.3 & 20.3040 & 0.4420 & 0.07 \\
\hline 34 & Sprayer & 20.0 & 38.5 & 11.1600 & 0.4132 & 0.07 \\
\hline 35 & Sprayer & 14.1 & 34.6 & 9.2751 & 0.4971 & 0.07 \\
\hline 36 & Sprayer & 28.1 & 34.9 & 36.3176 & -0.0117 & 0.04 \\
\hline 37 & Sprayer & 28.1 & 47.1 & 45.6961 & 0.0094 & 0.04 \\
\hline 38 & Sprayer & 20.4 & 35.0 & 7.8935 & 0.4936 & 0.07 \\
\hline 39 & Sprayer & 20.4 & 44.3 & 9.3702 & 0.5151 & 0.07 \\
\hline 40 & Sprayer & 20.4 & 29.2 & 7.0813 & 0.4695 & 0.07 \\
\hline 41 & Dripper-in & 10.0 & 4.0 & 1.1610 & 0.5371 & 0.05 \\
\hline
\end{tabular}


system (Fig. 2) was not modified but pipe sizes were calculated following the methodology described by Pedras et al. (2008).

Table 2 shows the main characteristics of emitters relative to the design alternatives: the discharge coefficient, $K_{e}$, the discharge exponent, $x$, the flow rate, $q\left(\mathrm{~L} \mathrm{~h}^{-1}\right)$, the pressure head, $H(m)$, and the coefficient of manufacturing variation, $C_{v}$. Data were obtained from manufacturers' and dealers' catalogues.

The target EU value used for sizing the pipe system was $95 \%$. However, this value was not achieved for all alternatives. The reason for a high target EU is to assess the model ability to solve adversative objectives because high EU is associated with high system costs which are contrary to their minimization. Table 3 presents selected results of pipe sizing calculations including pipe diameters, related pressure heads and information about the need to adopt pressure regulators. The maximum allowed pressure head variation in the mainline was $10 \mathrm{~m}$. The allowed pressure head variation in the laterals and manifolds depends upon the average flow rate of the emitter and the pretended emission uniformity EU (Pedras et al., 2008); thus, they vary with the considered alternative (e.g., for the alternative 4, the allowed pressure head variation in the laterals and manifolds are 1.0 and $0.481 \mathrm{~m}$, respectively). All the alternatives were simulated to determine their performance indicators used in the multicriteria analysis, which are presented in Table 4.

The best emission uniformity (EU) values in Table 4 correspond to pressure-compensating drippers and sprayers; the respective alternatives also show the best values for the percentage of deficit relative to the required irrigation $\left(P_{D}\right)$ and the volume of percolated water $\left(V_{p}\right)$, that is the indicator for potential contamination with nitrates and agrochemicals. These emitters are more expensive than non-compensating emitters, but the diameters of the piping system are smaller, so producing slightly higher annual fixed cost, AFC, than the alternatives with non-compensating emitters. Alternatives with sprayers have higher AFC due to the need for larger diameter of laterals; however, the total costs are compensated because they use a single lateral per crop row while two laterals per crop row are required for drippers. Summarizing, all alternatives have characteristics in favour of one or another criteria that make it difficult to select the best one without adopting MCA.

\subsection{Ranking when adopting the farmer's options}

The weights and discordance threshold values adopted to select the best alternative in agreement with the farmer's options are given in Table 5 . Weights represent a balance among the different criteria: $31 \%$ to criteria relative to minimizing costs (but giving a higher weight to investment costs $A F C), 37 \%$ to criteria that may lead to higher irrigation and fertigation uniformity (EU, SC and STV), $18 \%$ to the criterion relative to percolation of water and solutes $\left(\mathrm{V}_{\mathrm{p}}\right)$, and $14 \%$ to the criterion relative to precision water application that relates to maximize yields $\left(P_{D}\right)$.

The discordance thresholds $\left(D_{1}\right.$ and $\left.D_{2}\right)$ were selected for each criterion considering the range of variation of the indicator $D_{A B}$ (Eq. 7 in Pedras et al., 2008) when $D_{1}>D_{2}$. The concordance thresholds were $c^{+}=0.6 ; c^{0}=0.55 ; c^{-}=0.5$, which were selected from central values defined in the range $[0,1]$. Concordance and discordance values are computed by the model and proposed to the user.

Weights assigned to minimizing costs reflect the farmers need to get a good system with an investment as low as possible and with reduced operation and maintenance costs. However, these weights are relatively low because there is also the need to satisfy environment constraints, mainly the control of groundwater contamination with nitrates. In fact, the orchard is located in a Nitrate Vulnerable Zone and the irrigation water is supplied from a borehole with $\mathrm{NO}_{3}{ }^{-}$ concentration $>100 \mathrm{mg} \mathrm{L}^{-1}$ (Stigter et al., 2006). To achieve this control, there is the need to adopt good quality equipment, which is considered by the criteria relative to

\section{Table 3 - Main characteristics of the pipe systems for the considered alternatives.}

\begin{tabular}{|c|c|c|c|c|c|}
\hline $\begin{array}{l}\text { Alternative } \\
\text { number }\end{array}$ & $\begin{array}{c}\text { Mainline } \\
\text { diameter }(\mathrm{mm})\end{array}$ & $\begin{array}{c}\text { Manifold } \\
\text { diameter }(\mathrm{mm})\end{array}$ & $\begin{array}{c}\text { Lateral } \\
\text { diameter }(\mathrm{mm})\end{array}$ & $\begin{array}{l}\text { Pressure head at } \\
\text { the upstream end (m) }\end{array}$ & $\begin{array}{l}\text { Pressure regulator } \\
\text { and size }(\mathrm{m})\end{array}$ \\
\hline $1 ; 2 ; 3 ; 30$ & 83.0 & 83.0 & 13.2 & $15.4 ; 16.6 ; 15.0 ; 16.1$ & No \\
\hline $4 ; 5$ & 83.0 & 83.0 & $14.8 ; 14.2$ & 15.0 & No \\
\hline $6 ; 23 ; 24 ; 27 ; 29$ & 69.2 & 63.0 & 13.2 & 19.6; 20.0; 19.6; 18.9; 19.7 & No \\
\hline $7 ; 17 ; 26$ & 101.6 & 101.6 & 13.8 & $13.6 ; 13.4 ; 13.6$ & No \\
\hline $8 ; 10 ; 19$ & 83.0 & $83.0 ; 63.0 ; 83.0$ & $17.6 ; 17.6 ; 17.7$ & $14.0 ; 16.1,14.3$ & No \\
\hline $9 ; 22$ & 69.2 & 63.0 & $14.8 ; 13.8$ & $18.8 ; 19.0$ & No \\
\hline $11 ; 12 ; 13$ & 69.2 & 63.0 & $14.1 ; 14.6 ; 17.6$ & 18.4 & No \\
\hline $14 ; 20$ & 101.6 & 101.6 & $13.2 ; 17.6$ & $13.3 ; 13.7$ & No \\
\hline $15 ; 16$ & 83.0 & 83.0 & 10.4 & $13.8 ; 14.0$ & No \\
\hline $18 ; 41$ & 83.0 & 83.0 & $13.8 ; 13.9$ & $15.3 ; 15.6$ & No \\
\hline $21 ; 25$ & 83.0 & 83.0 & 17.6 & $14.2 ; 14.9$ & No \\
\hline 28 & 69.2 & 63.0 & 13.9 & 19.0 & No \\
\hline 32 & 101.6 & 83.0 & 28.8 & 25.8 & 20.0 \\
\hline 33 & 125.0 & 101.6 & 28.8 & 27.8 & 20.0 \\
\hline $34 ; 38$ & 83.0 & 83.0 & 28.8 & $29.30 ; 30.2$ & 20.0; 20.4 \\
\hline $35 ; 40$ & 83.0 & 83.0 & 21.0 & $22.8 ; 27.0$ & $14.1 ; 20.1$ \\
\hline $36 ; 31$ & 83.0 & 69.2 & 21.0 & $28.5 ; 36.9$ & No \\
\hline $37 ; 39$ & 101.6 & $83.0 ; 101.6$ & 21.0 & $34.5 ; 26.3$ & $0 ; 20.4$ \\
\hline
\end{tabular}


Table 4 - Criteria attributes relative to the design alternatives.

\begin{tabular}{|c|c|c|c|c|c|c|c|}
\hline \multirow[t]{2}{*}{ Alternative } & \multicolumn{2}{|c|}{ Economic } & \multirow{2}{*}{$\begin{array}{c}\text { Yield } \\
\text { Percentage of } \\
\text { irrigation } \\
\text { deficit, } P_{\mathrm{D}}(\%)\end{array}$} & \multirow{2}{*}{$\begin{array}{c}\text { Environment } \\
\text { Volume of } \\
\text { percolated water, } \\
\mathrm{V}_{\mathrm{p}}\left(\mathrm{mm}^{\mathrm{mear}}{ }^{-1}\right)\end{array}$} & \multicolumn{3}{|c|}{ Irrigation performance } \\
\hline & $\begin{array}{l}\text { Annual fixed } \\
\text { cost, AFC } \\
\left(€ \text { year }^{-1}\right)^{\mathrm{a}}\end{array}$ & $\begin{array}{l}\text { Operation and } \\
\text { maintenance cost, } \\
\text { OMC }\left(€ \text { year }^{-1}\right)^{\mathrm{a}}\end{array}$ & & & $\begin{array}{l}\text { Emission } \\
\text { uniformity, } \\
\text { EU (\%) }\end{array}$ & $\begin{array}{l}\text { Sensitivity } \\
\text { to clogging, } \\
\text { SC }^{\mathrm{b}}\end{array}$ & $\begin{array}{c}\text { Sensitivity to } \\
\text { temperature } \\
\text { variation } \text { STV }^{\mathrm{c}}\end{array}$ \\
\hline 1 & 637 & 332 & 1.49 & 21.2 & 93.4 & 1 & 0.00 \\
\hline 2 & 670 & 344 & 1.47 & 20.9 & 93.6 & 2 & 0.03 \\
\hline 3 & 543 & 321 & 1.52 & 21.7 & 93.3 & 1 & 0.02 \\
\hline 4 & 396 & 323 & 1.37 & 19.5 & 93.9 & 1 & 0.00 \\
\hline 5 & 417 & 324 & 1.35 & 19.3 & 93.9 & 1 & 0.00 \\
\hline 6 & 533 & 394 & 0.91 & 13.0 & 95.5 & 3 & 0.55 \\
\hline 7 & 487 & 303 & 1.30 & 18.6 & 94.0 & 1 & 0.02 \\
\hline 8 & 501 & 327 & 1.52 & 21.6 & 92.4 & 1 & 0.00 \\
\hline 9 & 511 & 392 & 0.15 & 2.2 & 99.4 & 3 & 0.48 \\
\hline 10 & 644 & 353 & 0.31 & 4.4 & 98.9 & 3 & 0.47 \\
\hline 11 & 553 & 388 & 0.10 & 1.4 & 99.6 & 3 & 0.49 \\
\hline 12 & 594 & 390 & 0.09 & 1.3 & 99.6 & 3 & 0.49 \\
\hline 13 & 615 & 391 & 0.09 & 1.3 & 99.6 & 3 & 0.49 \\
\hline 14 & 559 & 293 & 1.23 & 17.5 & 94.3 & 3 & 0.06 \\
\hline 15 & 376 & 306 & 2.15 & 30.7 & 92.0 & 2 & 0.04 \\
\hline 16 & 396 & 303 & 2.03 & 28.9 & 92.1 & 2 & 0.01 \\
\hline 17 & 434 & 298 & 1.26 & 18.0 & 94.1 & 2 & 0.00 \\
\hline 18 & 449 & 330 & 1.36 & 19.4 & 93.9 & 2 & 0.02 \\
\hline 19 & 470 & 315 & 1.51 & 21.4 & 92.1 & 2 & 0.00 \\
\hline 20 & 486 & 306 & 1.34 & 19.0 & 93.7 & 2 & 0.00 \\
\hline 21 & 501 & 316 & 1.48 & 21.1 & 92.1 & 2 & 0.00 \\
\hline 22 & 505 & 395 & 0.46 & 6.6 & 98.3 & 3 & 0.44 \\
\hline 23 & 604 & 404 & 0.68 & 9.7 & 97.2 & 2 & 0.36 \\
\hline 24 & 615 & 400 & 0.14 & 2.1 & 99.2 & 3 & 0.51 \\
\hline 25 & 544 & 327 & 1.52 & 21.6 & 92.4 & 1 & 0.00 \\
\hline 26 & 465 & 303 & 1.30 & 18.6 & 94.0 & 1 & 0.02 \\
\hline 27 & 584 & 388 & 0.65 & 9.3 & 97.5 & 3 & 0.40 \\
\hline 28 & 657 & 403 & 0.22 & 3.1 & 99.2 & 3 & 0.47 \\
\hline 29 & 856 & 414 & 0.26 & 3.7 & 99.0 & 3 & 0.48 \\
\hline 30 & 650 & 341 & 1.48 & 21.0 & 93.6 & 3 & 0.00 \\
\hline 31 & 506 & 488 & 1.07 & 15.2 & 96.4 & 2 & 0.04 \\
\hline 32 & 663 & 445 & 0.87 & 12.4 & 96.4 & 1 & 0.04 \\
\hline 33 & 662 & 477 & 0.80 & 11.4 & 97.1 & 2 & 0.06 \\
\hline 34 & 720 & 519 & 0.72 & 10.2 & 96.8 & 2 & 0.09 \\
\hline 35 & 664 & 403 & 0.97 & 13.9 & 96.1 & 2 & 0.00 \\
\hline 36 & 708 & 630 & 0.02 & 0.3 & 99.8 & 2 & 0.51 \\
\hline 37 & 755 & 592 & 0.02 & 0.3 & 99.9 & 2 & 0.49 \\
\hline 38 & 715 & 504 & 0.79 & 11.2 & 96.3 & 2 & 0.00 \\
\hline 39 & 729 & 456 & 0.58 & 8.3 & 97.5 & 2 & 0.02 \\
\hline 40 & 652 & 470 & 0.57 & 8.2 & 97.6 & 2 & 0.03 \\
\hline 41 & 499 & 338 & 1.48 & 21.1 & 93.4 & 2 & 0.04 \\
\hline
\end{tabular}

Table 5 - Weights and discordance thresholds assigned to all criteria for selection of alternatives in agreement with the farmer's options.

\begin{tabular}{|c|c|c|c|c|c|c|c|}
\hline \multirow[t]{2}{*}{ Parameters } & \multicolumn{7}{|c|}{ Criteria } \\
\hline & $\begin{array}{l}\text { Annual fixed } \\
\text { cost, AFC } \\
\left(€ \text { year }^{-1}\right)\end{array}$ & $\begin{array}{c}\text { Operation } \\
\text { and maintenance } \\
\text { cost, OMC }\left(€ \text { year }^{-1}\right)\end{array}$ & $\begin{array}{l}\text { Percentage of } \\
\text { irrigation } \\
\text { deficit, } P_{D}(\%)\end{array}$ & $\begin{array}{c}\text { Volume of } \\
\text { percolated water, } \\
\mathrm{V}_{\mathrm{p}}\left(\mathrm{mm} \text { year }^{-1}\right)\end{array}$ & $\begin{array}{l}\text { Emission } \\
\text { uniformity, } \\
\text { EU (\%) }\end{array}$ & $\begin{array}{l}\text { Sensitivity to } \\
\text { clogging, SC }\end{array}$ & $\begin{array}{l}\text { Sensitivity to } \\
\text { temperature } \\
\text { variation, STV }\end{array}$ \\
\hline Weights (\%) & 18 & 13 & 14 & 18 & 11 & 15 & 11 \\
\hline $\begin{array}{l}\text { Discordance } \\
\text { threshold D1 }\end{array}$ & 230 & 280 & 1.8 & 9.5 & 6 & 1.5 & 0.5 \\
\hline $\begin{array}{l}\text { Discordance } \\
\text { threshold D2 }\end{array}$ & 100 & 30 & 0.6 & 1.9 & 2 & 0.2 & 0.06 \\
\hline
\end{tabular}


Table 6 - Ranking of the design alternatives.

\begin{tabular}{|c|c|c|c|c|c|}
\hline Ranking & Alternative & Ranking & Alternative & Ranking & Alternative \\
\hline 1 & 12 & 14 & 39 & 29 & 18 \\
\hline 2 & 13 & 15 & 23 & $30 / 31$ & $4 ; 30$ \\
\hline 3 & 11 & 16 & 38 & 32 & 2 \\
\hline 4 & 9 & 17 & 33 & 33 & 41 \\
\hline 5 & 24 & 18 & 32 & 34 & 21 \\
\hline 6 & 37 & $19 / 20$ & $6 ; 35$ & 35 & 19 \\
\hline 7 & 28 & 21 & 31 & 36 & 1 \\
\hline 8 & 36 & 22 & 14 & 37 & 8 \\
\hline 9 & 10 & $23 / 24$ & $17 ; 34$ & 38 & 3 \\
\hline 10 & 29 & 25 & 26 & 39 & 16 \\
\hline 11 & 22 & 25 & 7 & 40 & 25 \\
\hline 12 & 40 & 27 & 20 & 41 & 15 \\
\hline 13 & 27 & 28 & 5 & & \\
\hline
\end{tabular}

SC and STV, as well as a good design leading to high EU and small $\mathrm{V}_{\mathrm{p}}$.

The resulting ranking (Table 6) shows a clear order of the alternatives. The first eleven positions refer to alternatives with pressure-compensating drippers, with the exception of alternatives 36 and 37 that refer to pressure-compensating microsprayers. All these emitters have low sensitivity to clogging and to temperature variation. All eleven alternatives have high EU values but their investment costs, AFC, and operation and maintenance cost, OMC, are medium ranked; lower AFC and OMC values refer to alternatives with noncompensating drippers while higher AFC and OMC values are obtained with microsprayers.

\subsection{Sensitivity analysis relative to the weights assigned to the criteria}

A sensitivity analysis was performed to assess how changes in the weights assigned to the criteria would change the ranking of the alternatives. The discordance and concordance thresholds used for the ranking analysed above were kept constant in this sensitivity analysis. The scenarios A to $G$, corresponding to different weights assigned to each criterion, which represent different priorities given to the criteria, are shown in Table 7. The resulting rankings are given in Table 8.

Results show that assigning different weights (priorities) to the criteria leads to different rankings, i.e., the model is sensitive to these weights. Moreover, ranking is clearly defined for all cases. Ranking relative to scenarios A and C are similar to that of the base solution analysed before (Table 6), mainly referring to the top ranked alternatives. The top ranking is also not very different for scenarios $\mathrm{E}$ and $\mathrm{F}$. This means that using different options on weights may help to confirm rankings and therefore to select the best design alternative.

For all scenarios but scenario B, the alternatives are grouped relatively to the emitter type. In general, the compensating emitters are ranked first, then sprayers and finally the non-compensating drippers. In scenario B, where weights are heavily assigned to costs, the non-compensating drippers rank on the top because they are less costly. In scenario $\mathrm{D}$, where the priority is for maximizing yields, the top of the rank correspond to compensating microsprayers (alternatives 36 and 37) followed by compensating drippers since microsprayers are able to produce a better wetting of the trees root zone. In scenario $G$, where the priority is to minimize percolation, the top of the rank is for compensating sprayers, followed by the alternatives with compensating drippers, because the soil depth wetted by microsprayers is more uniform than with drippers.

Compensating drippers (alternatives 11-13) rank on the top for scenarios A, C, E and F like for the base solution (Table 6). This indicates that these alternatives are those that better make a trade-off between uniformity of water application, minimizing costs, maximizing yields and controlling percolation out of the root zone. These results indicate that it is advisable for the decision-maker to perform the ranking

\section{Table 7 - Scenarios on weights assigned to the criteria.}

\begin{tabular}{|c|c|c|c|c|c|c|c|}
\hline \multirow[t]{2}{*}{ Scenarios } & \multicolumn{7}{|c|}{ Criteria weights (\%) } \\
\hline & AFC & OMC & $P_{\mathrm{D}}$ & $V_{p}$ & EU & SC & STV \\
\hline A-balanced weights & 12 & 18 & 17 & 15 & 12 & 14 & 12 \\
\hline B-priority for minimizing investment costs & 36 & 10 & 10 & 14 & 10 & 10 & 10 \\
\hline C-priority for system uniformity & 14 & 10 & 12 & 13 & 18 & 18 & 15 \\
\hline D-priority for maximizing yields & 11 & 14 & 25 & 13 & 13 & 14 & 10 \\
\hline E-priority for minimizing costs \& environmental impacts & 20 & 20 & 9 & 26 & 8 & 9 & 8 \\
\hline F-priority for minimizing costs and maximizing yields & 20 & 23 & 27 & 8 & 7 & 8 & 7 \\
\hline G-priority to minimize percolation & 15 & 15 & 7 & 42 & 7 & 7 & 7 \\
\hline
\end{tabular}

AFC-annual fixed cost; OMC-operation and maintenance cost; $P_{\mathrm{D}}-$ percentage of deficit relative to the required irrigation; $\mathrm{V}_{\mathrm{p}}-\mathrm{volume}$ of water percolated indicating the potential contamination with nitrates and agricultural chemicals; EU-emission uniformity; SC-emitters sensitivity to clogging; STV-emitters sensitivity to temperature variation. 
Table 8 - Ranking of the alternatives ${ }^{a}$ for different scenarios of criteria weights.

\begin{tabular}{|c|c|c|c|c|c|c|c|}
\hline \multirow[t]{2}{*}{ Rank } & \multicolumn{7}{|c|}{ Scenarios } \\
\hline & A & B & C & $\mathrm{D}$ & $E$ & F & G \\
\hline 1 & 12 & 17 & 12 & 37 & 11 & 11 & 37 \\
\hline 2 & 13 & 4 & 13 & 36 & 12 & 12 & 36 \\
\hline 3 & 11 & $5 ; 16$ & 11 & 12 & 13 & 13 & 13 \\
\hline 4 & 9 & 22 & 9 & 13 & 9 & 9 & 12 \\
\hline 5 & 24 & 18 & 24 & 11 & 24 & 24 & 11 \\
\hline 6 & 28 & 9; 26 & 28 & 9 & $28 ; 37$ & 10 & 24 \\
\hline 7 & $10 ; 29$ & 20 & 37 & 24 & $10 ; 36$ & $22 ; 28$ & 9 \\
\hline 8 & 22 & 19 & 29 & 28 & 22 & 27 & 28 \\
\hline 9 & 40 & 11 & 36 & 29 & 29 & 37 & 29 \\
\hline 10 & $27 ; 39$ & 7 & 10 & 10 & 27 & 36 & 10 \\
\hline 11 & 23 & 41 & 22 & 22 & 40 & $23 ; 29$ & 22 \\
\hline 12 & $37 ; 38$ & 21 & 40 & 40 & 39 & 40 & 40 \\
\hline 13 & 33 & $\begin{array}{c}6 ; 8 ; 10 ; 12 ; \\
13 ; 14 ; 24 ; 27 \\
28 ; 31 ; 39 ; 40\end{array}$ & 27 & 39 & 23 & 6 & 39 \\
\hline 14 & 36 & 15 & 39 & 27 & 6 & 39 & 27 \\
\hline 15 & 32 & 3 & 23 & 23 & 33 & 33 & 23 \\
\hline 16 & $6 ; 35$ & 23 & 33 & $\begin{array}{l}6 ; 7 ; 14 ; 17 ; 26 ; \\
31 ; 32 ; 33 ; 34 ; \\
35 ; 38\end{array}$ & 32 & 32 & 34 \\
\hline 17 & 31 & 25 & 34 & 20 & 35 & 35 & 38 \\
\hline 18 & 14 & $30 ; 33 ; 37$ & 32 & 5 & 38 & 31 & 33 \\
\hline 19 & 17 & 1 & $6 ; 31 ; 35 ; 38$ & 18 & 31 & 14 & 32 \\
\hline 20 & $26 ; 34$ & 36 & 14 & $4 ; 30$ & 14 & 17 & $6 ; 35$ \\
\hline 21 & 7 & $29 ; 32$ & 17 & 2 & 17 & 26 & 31 \\
\hline 22 & 20 & 35 & 26 & 41 & 26 & 7 & 14 \\
\hline 23 & 5 & 38 & 7 & 21 & 7 & 20 & 17 \\
\hline 24 & 18 & 2 & 20 & 1 & 20 & 38 & 26 \\
\hline 25 & $4 ; 30$ & 34 & 5 & 19 & 34 & 4 & 7 \\
\hline 26 & 2 & & 18 & 8 & 4 & 5 & 20 \\
\hline 27 & 41 & & $4 ; 30$ & 3 & 5 & 18 & 5 \\
\hline 28 & 21 & & 2 & 25 & 18 & $16 ; 41$ & 18 \\
\hline 29 & 19 & & 41 & 16 & 41 & 21 & 4 \\
\hline 30 & 1 & & 19 & 15 & 30 & 30 & $2 ; 30$ \\
\hline 31 & 8 & & 21 & & 21 & 34 & 41 \\
\hline 32 & 3 & & 1 & & 19 & 19 & 21 \\
\hline 33 & 16 & & 8 & & 8 & 8 & 1 \\
\hline 34 & 25 & & $3 ; 16$ & & $2 ; 16$ & 15 & 19 \\
\hline 35 & 15 & & 25 & & $1 ; 3 ; 25$ & 2 & 8 \\
\hline 36 & & & 15 & & 15 & $1 ; 3 ; 25$ & 25 \\
\hline 37 & & & & & & & 3 \\
\hline 38 & & & & & & & 16 \\
\hline 39 & & & & & & & 15 \\
\hline
\end{tabular}

analysis adopting various options on priorities assigned to the criteria and select the best solution after comparing the observed rankings.

\subsection{Impacts on ranking due to concordance and discordance threshold values}

Table 9 shows a set of scenarios used for the sensitivity analysis of the concordance thresholds. These thresholds are increased from scenario C.a to C.h relative to the base condition used in the former sections $\left(c^{+}=0.6 ; c^{0}=0.55\right.$; $\left.c^{-}=0.5\right)$. Weights and discordance thresholds are those described in Table 5 and were kept constant. For the scenarios C.a to C.e the first 5 ranking positions do not change relative to the base solution (Table 6). The top ranking only changes for very high, uncommon values of $c^{+} ; c^{0} ; c^{-}$(Table 9); changes in ranking occur for lower positions only (data not shown). This indicates that the model produces quite stable ranking when the concordance values are within the expected range.

A sensitivity analysis was also carried out for the discordance thresholds (Table 10). For each criterion several $D_{2}$ values were analysed for each $D_{1}$, with $D_{1} \geq D_{2}$. The weights listed in Table 5 and related concordance values were kept constant, as well as the discordance values relative to all criteria but the criterion under analysis. Results show that changes in the discordance thresholds for the criteria AFC and OMC result in maintaining the five top ranking positions as for the base solution (Table 6); however, lower rankings change when discordance thresholds are considerably different than those selected (Table 5). When they become very different 


$\begin{aligned} & \text { Table 9 - Scenarios for the concordance thresholds and } \\
& \text { respective ranking results. }\end{aligned}$
\begin{tabular}{lllll} 
Scenarios & $c^{+}$ & $c^{0}$ & $c^{-}$ & \multicolumn{1}{c}{$\begin{array}{c}\text { Ranking } \\
\text { (first 6 positions) }\end{array}$} \\
\hline C.a & 1.0 & 0.55 & 0.5 & $12,13,11,9,24,22$ \\
C.b & 0.8 & 0.55 & 0.5 & $12,13,11,9,24,10$ \\
C.c & 0.7 & 0.55 & 0.5 & $12,13,11,9,24,28$ \\
C.d & 0.65 & 0.55 & 0.3 & $12,13,11,9,24,28$ \\
C.e & 0.75 & 0.6 & 0.55 & $12,13,11,9,24,28$ \\
C.f & 0.80 & 0.65 & 0.6 & $12,13,37,11,9 / 36,14$ \\
C.g & 0.9 & 0.75 & 0.65 & $12,13,11,9,24,28$ \\
C.h & 1 & 0.9 & 0.85 & $5 / 11 / 12 / 13 / 17,9,4 / 10 / 22$, \\
& & & & $18 / 20 / 24 / 26$ \\
\hline
\end{tabular}

${ }^{a}$ When two or more alternatives are separated by/it indicates that they are equally ranked.

(case when $D_{1}=D_{2}=50$ ) then the top five positions also change. Relative to the criteria $P_{D}, V_{p}$, EU and SC, changes in thresholds $D_{1}$ and $D_{2}$ do not lead to changes in the ranking relative to the base solution. Differently, large changes in $D_{1}$ and $D_{2}$ relative to STV greatly change rankings but the top five ranking positions are not altered if those changes are relatively small. However, mid ranking positions are affected.
The sensitivity analysis shows that rankings produced by MIRRIG model are stable and not sensitive to changes in concordance and discordance thresholds computed by the model except when the users would adopt values very different from those proposed by the model in a specific window (Pedras et al., 2008). However, this is not likely to occur, even for inexperienced users. Thus, it may be concluded that ranking computations are stable.

\section{Conclusions}

The case study application of the DSS MIRRIG to the design and selection of a microirrigation system for a citrus orchard was used to analyse how ranking of design alternatives responds to assigning different priorities and weights to the criteria adopted, i.e., according to the decision-maker preferences. Because the multicriteria analysis method ELECTRE II is a powerful tool for ranking the design alternatives, results show that by adopting different weights the ranking is altered. However, changes in ranking follow a logic related to the characteristics of each design alternative, easy to be interpreted by the user. It becomes possible for a user to adopt various sets of weights and select the best solution consider-

Table 10 - Scenarios assessed for various discordance thresholds $D_{1}$ and $D_{2}$ relative to every criterion and resulting rankings.

\begin{tabular}{|c|c|c|c|}
\hline Criteria & $D_{1}$ & $D_{2}$ & Ranking $^{\mathrm{a}}$ (first 6 positions) \\
\hline \multirow[t]{5}{*}{ AFC } & 230 & $30,50,150,200,230$ & $12,13,11.9,24,37$ \\
\hline & 200 & $30,50,100,150,200$ & $12,13,11.9,24,28 / 37$ \\
\hline & 150 & $30,50,100,150$ & $12,13,11.9,24,28 / 37$ \\
\hline & 100 & $30,50,100$ & $12,13,11.9,24,22 / 28$ \\
\hline & 50 & 50 & $12,11.17,9,13 / 22 / 26,31$ \\
\hline \multirow[t]{5}{*}{ OMC } & 280 & $50,100,150,200$ & $12,13,11.9,24,37$ \\
\hline & 200 & $30,50,100,150,200$ & $12,13,11.9,24,37$ \\
\hline & 150 & $30,50,100,150$ & $12,13,11.9,24,28$ \\
\hline & 100 & $30,50,100$ & $12,13,11.9,24,28$ \\
\hline & 50 & 50 & $12,13,11 / 14.9,17,24$ \\
\hline \multirow[t]{4}{*}{$P_{\mathrm{D}}$} & 1.8 & $0.4,0.7,1.3,1.8$ & No changes relative to the base ranking $12,13,11.9,24,37$ \\
\hline & 1.3 & $0.4,0.7,1.3$ & \\
\hline & 0.7 & $0.4,0.7$ & \\
\hline & 0.3 & 0.3 & \\
\hline \multirow[t]{3}{*}{$v_{\mathrm{p}}$} & 9.5 & $1.1,3.0,5.7,9.5$ & \\
\hline & 5.7 & $1.1,3.0,5.7$ & \\
\hline & 3.0 & $1.1,3.0$ & \\
\hline \multirow[t]{3}{*}{ EU } & 6 & $1,3,4,5,6$ & \\
\hline & 4 & $1,3,4$ & \\
\hline & 2 & 1,2 & \\
\hline \multirow[t]{4}{*}{ SC } & 1.5 & $0.1,0.4,0.6,1.0,1.5$ & \\
\hline & 1.0 & $0.1,0.4,0.6,1.0$ & \\
\hline & 0.5 & $0.1,0.4$ & \\
\hline & 0.4 & $0.1,0.2$ & \\
\hline \multirow[t]{4}{*}{ STV } & 0.4 & $0.02,0.08,0.1,0.2,0.3,0.4$ & $12,13,11.9,24,37$ \\
\hline & 0.2 & $0.02,0.08,0.1,0.2$ & $12,13,11.9 / 40,24,28 / 39$ \\
\hline & 0.1 & $0.02,0.08,0.1$ & $40,12 / 39,4 / 5 / 7 / 13 / 14 / 17 / 18 / 20 / 26 / 31 / 32 / 33 / 34 / 35 / 38,11 / 30,2 / 9,41$ \\
\hline & 0.08 & $0.02,0.08$ & $40,39,38,12 / 32,35$ \\
\hline
\end{tabular}

AFC-annual fixed cost; OMC-operation and maintenance cost; $P_{D}-$ percentage of deficit relative to the required irrigation; $V_{p}-v o l u m e$ of water percolated indicating the potential contamination with nitrates and agricultural chemicals; EU-emission uniformity; SC-emitters sensitivity to clogging; STV-emitters sensitivity to temperature variation.

${ }^{a}$ When two or more alternatives are separated by/it indicates that they are equally ranked. 
ing the resulting rankings. This allows a good dialogue between the designer and the farmer.

The solution selected by the farmer was taken as base solution for performing a sensitivity analysis relative to the concordance and discordance threshold values. Results have shown that the ranking produced by the model is stable when those parameter values are not very far from those proposed by the model. It allows to conclude that the model is relatively insensitive to the selection of this ranking parameters, which means that ranking is not likely to be affected due to inexperience of the users.

\section{Acknowledgements}

Field studies and its implementation in the south of Portugal were developed under the research project POCTI/AGG/42689/ 2001. The support of the Agricultural Engineering Research Center (CEER) is also acknowledged. Sincere thanks are due to Dr. Isabel L. Alves for carefully revising the manuscript.

\section{R E F E R E N C E S}

ASAE, 2006. ASAE EP405.1. Design and installation of microirrigation systems. In: ASAE Standards 2006. ASABE, St. Joseph, MI, pp. 942-946.
Barragan, J., Bralts, V., Wu, I.P., 2006. Assessment of emission uniformity for micro-irrigation design. Biosyst. Eng. 93 (1), 89-97.

Demir, V., Yurdem, H., Degirmecioglu, A., 2007. Development of prediction models for friction losses in drip irrigation laterals equipped with integrated in-line and on-line emitters using dimensional analysis. Biosyst. Eng. 96 (4), 617-631.

Keller, J., Bliesner, R.D., 1990. Sprinkle and Trickle Irrigation. Van Nostrand Reinhold, New York.

Pedras, C.M.G., Pereira, L.S., Gonçalves, J.M., 2008. MIRRIG: a decision support system for design and evaluation of microirrigation systems, Agric. Water Manage., doi:10.1016/ j.agwat.2008.10.006.

Pereira, L.S., Trout, T.J., 1999. Irrigation methods. In: Van Lier, H.N., Pereira, L.S., Steiner, F.R. (Eds.), CIGR Handbook of Agricultural Engineering. Vol. I. Land and Water Engineering, ASAE, St. Joseph, pp. 279-379.

Rodríguez-Sinobas, L., Juana, L., Losada, A., 1999. Effects of temperature changes on emitter discharge. J. Irrig. Drain. Eng. 125 (2), 64-73.

Roy, B., 1996. Multicriteria Methodology for Decision Aiding. Kluwer Academic Publishers, Dordrecht, The Netherlands.

Stigter, T.Y., Ribeiro, L., Dill, A.M.M.C., 2006. Application of a groundwater quality index as an assessment and communication tool in agro-environmental policies-two Portuguese case studies. J. Hydrol. 327 (3-4), 578-591.

Valiantzas, J.D., Dercas, N., Karantounias, G., 2007. Explicit optimum design of a simple irrigation delivery system. Trans. ASABE 50 (2), 429-438.

Wu, I.P., Barragan, J., 2000. Design criteria for microirrigation systems. Trans. ASAE 43 (5), 1145-1154. 